colonies grown on agar are grey-white and show in cross. section a typical plectenchymatic structure like that of a true sclerotium. As with Claviceps paspali, the mycelium of this strain grown in submerged culture has a cellular structure similar to that of a natural sclerotium. Ergot. amine production in submerged culture occurred in a culture medium of high osmotic pressure of the following composition: Mannitol 20 per cent; peptone-Difco 3 per cent; tap water; final $p \mathrm{H} 6 \cdot 2$. The culture medium was sterilized for $30 \mathrm{~min}$ at $110^{\circ} \mathrm{C}$. Cotton-wool plugged $500-\mathrm{ml}$. Erlenmeyer flasks containing $100 \mathrm{ml}$. of culture medium were used on a rotary shaker at $24^{\circ} \mathrm{C}(200$ r.p.m., eccentric throw $10 \mathrm{~cm}$ ). After $8-10$ days the total alkaloid content from the broth and mycelium ranged from 800 to $1,400 \mu \mathrm{g} / \mathrm{ml}$. (calculated as ergotamine). Chromatographic analysis of the alkaloids extracted from the culture medium showed ergotamine to be the principal component present.

I thank Prof. E. B. Chain for his continued interest in this work.

Department of Biochemistry,

\section{A. Tonolo*}

Imperial College of Science and Technology, London.

* On leave from the Istituto Superiore di Sanità, Rome.

'Arcamone, F., Bonino, C., Chain, E. B., Ferretti, A., Pennella, P., Tonolo, A., and Vero, L., Nature, 18\%, 238 (1960).

"Arcamone, F., Chain, E. B., Ferretti, A., Minghetti, A., Pennella, P. Tonolo, A., and Vero, L., Proc. Roy. Soc., B, 155, 26 (1961).

${ }^{3}$ Tonolo, A., Scotti, T., and Vero, L., Proc. First Intern. Fermentation Symp. - Sci. Reps. First Super. Sanità, i, 404 (1960).

\section{Further Proof of Direct Oxygen Transfer by Carotenoids in Respiration and Photosynthesis}

THE hypothesis that carotenoids participate in oxygen transfer in photosynthesis was first put forward by Warburg and Krippahl ${ }^{1}$, then by Cholnoky et al. ${ }^{2}$. Sapožnikov ${ }^{3}$ observed increased production of violaxanthin (a diepoxide of lutein) in darkness with a corresponding decrease in lutein production. In illuminated medium the opposite reaction occurred. Hydroxylamine, a wellknown inhibitor of photosynthesis, has been shown to retard this light-darkness reaction. Blass, Anderson and Calvin ${ }^{5}$ confirmed the work of Sapožnikov, but, although they observed the decrease of violaxanthin in light, they found no corresponding rise in the concentration of lutein. In these experiments, however, nearly equal specific radioactivity of lutein and violaxanthin was noted. This fact suggests an interrelationship between these two carotenoids in photosynthesis and respiration respectively. Recently, Saakov ${ }^{6}$ gave a complete scheme of the biosynthesis of carotenoids and of their oxido-reduction reactions in photosynthesis.

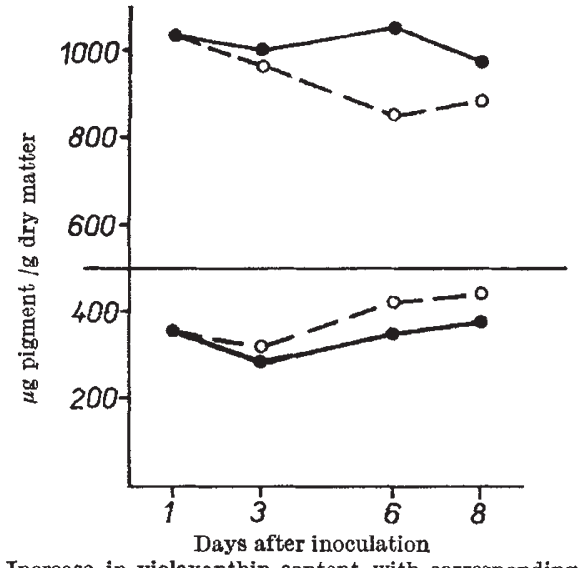

Fig. 1. Increase in violaxanthin content with corresponding decrease in lutein content in barley after infection with powdery mildew. Mean values of at least three determinations; maximal standard deviation for violaxanthin (bottom graphs): $\pm 0^{\circ} 009$; for lutein (top graphs): $\pm 0^{\circ} 043$. Control plants; $O--O$, infected plants

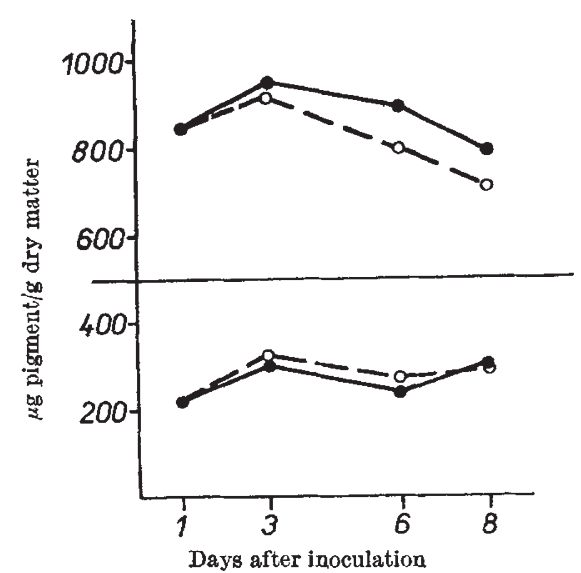

Fig. 2. Increase in neoxanthin content and decrease in $\beta$-carotene content in barley after infection with powdery mildew. Mean values of thin (bottom graphs): \pm 0.004 ; for $\beta$-carotene (top graphs): \pm 0.021 . \begin{tabular}{l}
, Control plants; $0-1-0$, infected plants \\
\hline
\end{tabular}

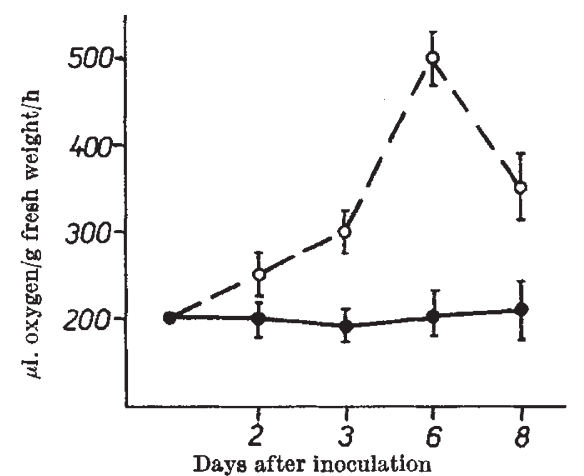

Fig. 3. Rise of respiration of barley after infection with powdery mildew. - Control plants; $O \ldots \ldots$, infected plants

During our investigations? ${ }^{7}$ of barley infected with powdery mildew (Erysiphe graminis f.sp. hordei Marchal, strain $C_{6}$ ) under standard conditions we observed increased content of violaxanthin immediately after infection with the fungus up to the sporulation time of the parasite. Together with the increase of violaxanthin content a corresponding decrease in lutein content was observed (Fig. 1). Increase of oxidized carotenoid with a corresponding drop in the content of the reduced form took place in the same phase of the disease, in which increased respiration of the host occurs. (Pigment analyses were made spectrophotometrically after thinlayer chromatography on silica gel.)

It may be mentioned that a decrease of $\beta$-carotene (mono-hydroxy- $\beta$-carotene) and a slight increase of neoxanthin (mono-epoxy-lutein) were also found during the period of increased respiration (Fig. 2).

These results may be regarded as further proof of direct oxygen transfer by carotenoids in photosynthesis and respiration.

I thank Mr. F. Frič for his assistance. Eimsabeth Haspel-Horvatovič

Botanical Institute of the Slovak Academy of Sciences,

Department of Pathological Physiology, Bratislava.

'Warburg, O., and Krippahl, G., Angero. Chem., 86, 493 (1954).

${ }^{2}$ Cholnoky, L., Györgyfy, Katherine, Nagy, Elisabeth, and Pánczel, Marta. Nature, 178,410 (1956).

${ }^{3}$ Sapožnikov, D. I., Krasovskaja, T. A., Majevskaja, D. V., and Popova, O. F., Dokl. Akad. Nauk S.S,S.R., 113, 465 (1957).

4 Sapožnikov, D. I., Ejdelman, E. M., Bažanova, D. V., and Popova, O. F., Dokl. Akad. Nauk S.S.S.R., 127, 1128 (1959).

- Blass, U., Anderson, J. M., and Calvin, M., Plant Physiol., 34, 329 (1959).

- Saakov, V. S., Dokl. Akad. Nauk S.S.S.R., 155, 1212 (1964).

${ }^{7}$ Haspelová-Horvatovičová, A., and Frié, F., Biologia (Bratislava), 19, 809 (1964). 